\title{
Implementation of a DB-Based Virtual File System for Lightweight IoT Clouds
}

\author{
Hyung-Bong Lee ${ }^{\dagger} \cdot \mathrm{Ki}-$ Hyeon Kwon ${ }^{+\dagger}$
}

\begin{abstract}
IoT(Internet of Things) is a concept of connected internet pursuing direct access to devices or sensors in fused environment of personal, industrial and public area. In IoT environment, it is possible to access realtime data, and the data format and topology of devices are diverse. Also, there are bidirectional communications between users and devices to control actuators in IoT. In this point, Io $\mathrm{T}$ is different from the conventional internet in which data are produced by human desktops and gathered in server systems by way of one-sided simple internet communications. For the cloud or portal service of IoT, there should be a file management framework supporting systematic naming service and unified data access interface encompassing the variety of IoT things. This paper implements a DB-based virtual file system maintaining attributes of IoT things in a UNIX-styled file system view. Users who logged in the virtual shell are able to explore IoT things by navigating the virtual file system, and able to access Io $\mathrm{T}$ things directly via UNIX-styled file I $\cdot \mathrm{O}$ APIs. The implemented virtual file system is lightweight and flexible because it maintains only directory structure and descriptors for the distributed IoT things. The result of a test for the virtual shell primitives such as mkdir() or chdir() shows the smooth functionality of the virtual file system, Also, the exploring performance of the file system is better than that of Window file system in case of adopting a simple directory cache mechanism.
\end{abstract}

Keywords : IoT(Internet of Things), Cloud Service, VFS(Virtual File System), DB-Based File System

\section{경량 사물 인터넷 클라우드를 위한 $\mathrm{DB}$ 기반 가상 파일 시스템 구현 \\ 이 형 봉 $^{+}$권 기 현 ${ }^{++}$}

\begin{abstract}
요 약
사물 인터넷은 개인, 산업, 공공 분야를 망라하여 각 분야의 말단 기기나 센서에 대한 직접 접근을 추구하는 상시 연결 인터넷 개념이다. 사 물 인터넷에서는 실시간 데이터 접근이 가능하고, 디바이스의 데이터 포맷과 구성 형태가 다양하다. 또한, 사물 인터넷 환경에서는 기기 제어를 위한 양방향 통신이 이루어지기도 한다. 이런 관점에서, 사물 인터넷은 주로 인간이 사용하는 데스크톱에서 생성된 데이터가 간단하고 일방적 인 인터넷 통신을 통해 서버에 집중되는 기존 인터넷과 대비된다. 이러한 사물 인터넷의 클라우드 혹은 포털 서비스를 위해서는 분산된 디바이 스들에 대한 체계적인 명명 서비스와 이들의 다양성을 포용할 수 있는 일관된 접근 인터페이스를 제공하는 파일 관리 프레임이 요구된다. 이 연구에서는 사물 인터넷 구성요소의 속성 정보를 유닉스 스타일의 파일 시스템 뷰로 관리하는 $\mathrm{DB}$ 기반 가상 파일 시스템을 구현한다. 구현된 가상 셀에 로그인한 사용자들은 가상 파일 시스템을 항해함으로써 사물 인터넷 구성요소를 탐색할 수 있고, 유닉스 스타일의 파일 입·출력 $\mathrm{API}$ 를 이용하여 디바이스에 직접 접근할 수 있다. 구현된 $\mathrm{DB}$ 기반 가상 파일 시스템은 디렉터리 체계와 분산된 데이터 및 디바이스에 대한 지시자만을 관리하므로 가볍고 유연하다. $\operatorname{Mkdir}(), \operatorname{chdir}()$ 등 구현된 주요 가상 쉘 프리미티브에 대한 시험 결과, 구현된 가상 파일 시스템의 원활한 기능이 검증되었다. 그리고 구현 파일 시스템에 간단한 디렉터리 캐시 기법을 적용한 경우 윈도우 운영체제 파일 시스템보다 더 우수한 탐색 성능을 보였다.
\end{abstract}

키워드 : 사물 인터넷, 클라우드 서비스, 가상 파일 시스템, DB 기반 파일 시스템

† 종신회원 : 강릉원주대학교 컴퓨터공학과 교수

† 정 회 원 : 강원대학교 전자정보통신공학부 교수

Manuscript Received: August 12, 2014

First Revision : September 25, 2014

Accepted: October 6, 2014

* Corresponding Author:Ki-Hyeon Kwon(kweon@kangwon.ac.kr)

\section{1. 서 론}

사물 인터넷(IoT: Internet of Things)의 사전적 의미는 “인터넷을 통해 접근되는 물리적 객체들의 네트워크”로 정 
의된다. 그런데 여기에 포함된 물리적 객체들이 돌이나 나 무처럼 아무런 정보활동이 없는 것들이라면 그 네트워크의 존재가치는 무용지물임에 틀림없다. 이런 관점에서 사물 인 터넷의 개념은 "인간, 사물, 서비스의 세 가지 분산된 환경 요소들이 인간의 명시적 개입이 없더라도 상호 협력적으로 센싱, 네트워킹, 정보 처리 등 지능적 관계를 형성하는 사물 공간 연결망”으로 해석할 수 있다[1]. 여기서의 사물에는 일 반 유-무선 네트워크에서의 단말기는 물론 정보를 생산하 거나 소모하는 인간, 차량, 교량, 문화재, 기상 모니터링 시 스템 등 개인이나 산업, 그리고 공공 분야를 망라하여 주위 환경을 구성하는 물리적 사물 등이 포함된다. 사물 인터넷 은 2000년대 초반 M2M(Machine-to-Machine), USN(Ubiquitous Sensor Network) 등의 이름으로 시작하여 이미 정부 가 추진하는 신성장 동력의 한 축으로 자리하고 있다[2].

사물 인터넷을 위한 3대 주요 요소 기술로서 센싱 기술, 유무선 통신 및 네트워크 인프라 기술, 사물 인터넷 서비스 인터페이스 기술을 들 수 있는데, 이 중 서비스 인터페이스 기술은 사물 인터넷의 구성요소인 인간, 사물, 서비스를 특 정 응용 서비스와 연계하는 역할을 수행하는 부분으로[1], 사물 인터넷을 포털 혹은 클라우드 컴퓨팅 차원으로 확장시 키기 위한 기반 기술이라 말할 수 있다. 클라우드 컴퓨팅이 란 "언제 어디서나 무엇이든(유비쿼터스), 그리고 편리하게, 재구성 가능한 공유된 컴퓨팅 자원에 대한 네트워크 접근을 추구하는 컴퓨팅 서비스 모델" $[3,4]$ 로 정의되는데, 여기서 서비스 모델은 소프트웨어형(SaaS: Software as a Service), 플랫폼형(PaaS: Platform as a Service), 기반구조형(IaaS: Infrastructure as a Service) 등 크게 세 가지로 분류된다 [5]. 각 유형별 정보시스템 계층 구성도는 Fig. 1과 같다. 이 그림으로부터, IaaS는 운영체제가 설치될 수 있는 컴퓨팅 자원으로, Paas는 응용 프로그램이 설치될 수 있는 운영 환 경으로, 그리고 $\mathrm{SaaS}$ 는 응용 소프트웨어로 각각 요약될 수 있다.

최근 일반인들이 가장 실감나게 체험하고 있는 클라우드 서비스 중의 하나로 각종 인터넷 포털 사이트의 이메일 서 비스를 들 수 있다. 이를테면 구글의 G메일은 지역적으로 분산된 엄청난 규모의 저장 공간을 분산 파일 시스템으로 구축하여 사용자들에게 메일링 소프트웨어 서비스를 제공하 고 있는데[6], 이는 $\mathrm{SaaS}$ 형 클라우드 서비스에 해당된다. 반 면에, Dropbox는 PC나 스마트폰 구별 없이 인터넷상에 가 상 저장 공간을 제공함으로써 인터넷이 있는 곳이면 어디에

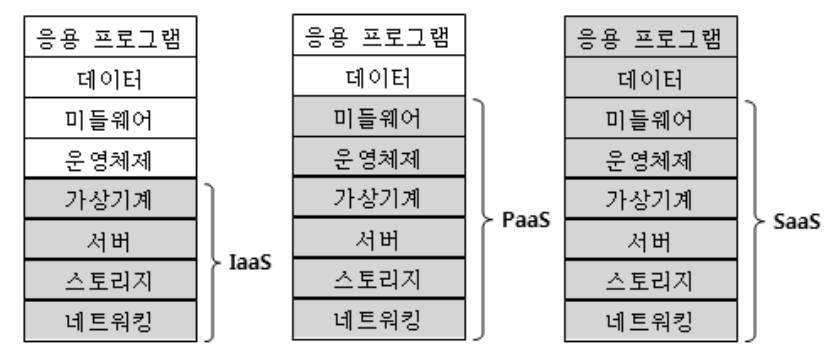

Fig. 1. Classification of Cloud Computing Services
서도 동일한 뷰(view)로 접근할 수 있는데[3], 이는 PaaS형 클라우드 서비스에 해당된다. 그 밖에 VMware 등 가상 기 계 플랫폼은 IaaS 서비스의 일종이다.

이 논문은 사물 인터넷 데이터에 대한 클라우드 차원의 관리 및 접근 서비스에 적합한 서버 프레임, 즉 $\mathrm{PaaS}$ 형 클 라우드 서비스를 위한 시스템 플랫폼을 구현한다. 이 플랫 폼은 $\mathrm{DB}$ 기반 가상 유닉스 파일 시스템을 [7]에 소개됐던 기초 개념을 완성하여 적용하되, 파일 시스템의 운영 및 사 물 인터넷 데이터의 유형별 접근 프로시저를 특정 운영체제 와 독립적인 미들웨어 수준에서 구현한다. 구현 가상 파일 시스템의 일차적 활용 목표는 1000 개 내 - 외의 USN 게이트 웨이로 구성된 중규모 센서 네트워크의 클라우드 서비스에 둔다. 이를 위하여 2절에서 관련 연구를 살펴보고, 3절에서 $\mathrm{DB}$ 기반 가상 파일 시스템을 설계하며, 4절에서는 구현 및 검증을 하고, 마지막 5절에서 결론 및 향후 계획으로 끝맺 는다.

\section{2. 관련 연구}

\section{1 빅데이터, 사물 인터넷, 클라우드}

빅데이터란 "기존의 데이터베이스 관리도구로 데이터를 수집, 저장, 관리, 분석할 수 있는 역량을 넘어서는 대량의 정형 또는 비정형 데이터의 집합”이다 $[8,9]$. 즉, 빅데이터는 수집 경로를 거쳐 수신된 대용량 데이터를 어떻게 효율적으 로 관리하고 활용할 것인가에 초점을 둔 개념으로 주로 데 이터베이스 차원에서의 논점이다. 이른바 $3 \mathrm{~V}$ (Volume, Variety, Velocity) 모델[10]이라는 빅데이터 특성은 빅데이 터의 관심이 데이터 소스에서 데이터베이스까지의 이동 과 정보다는 시스템에 도달한 방대한 데이터의 관리 및 분석에 있음을 잘 보여주고 있다. 이에 따라, 빅데이터 관련 연구는 대용량 데이터의 입 - 출력 성능 개선[11], 대용량 저장방법 [12], 질의 성능 향상[13], 분석 어플리케이션 방법론[14] 등 에 집중된다.

사물 인터넷은 인터넷 단말이 주로 인간이 사용하는 데스 크톱이었던 과거 환경과 다르게, 오늘날 급속하게 팽창하고 있는 기기 단말(디바이스) 위주의 인터넷이기 때문에, 이런 환경에서는 대용량 측면보다는 데이터 구조 및 데이터 취득 방법의 다양성 극복 방안이 더 중요하다. 이에 관한 연구 [15]들이 이제 막 시작되고 있다. 특히, 사물 인터넷의 구성 요소들은 고유 $\mathrm{id}$, 위치, 기능 등 다양한 속성 기준에 의해 서 식별되어야 하고, 무선 노드, 가변 데이터 형식, 동시 운 용 장치들로부터의 데이터의 합류 등 이질적인 성질로 인해 현재의 개별적이고 정적인 URL 기반 명명 서비스만으로는 한계가 있지만[16], 이 분야 역시 연구가 활발하지 못하다. [17]은 인터넷 환경에서 계정 관리 등에 널리 활용되는 LDAP(Lightweight Directory Access Protocol)의 기능 개념 을 바탕으로, 이질적인 센서나 액추에이터의 설치 및 설정 에 따른 작명 방안과 명명 서비스, 분리된 사물 인터넷 도 
메인 간의 명칭 변환 서비스 등을 위한 미들웨어 차원의 서 버 구조를 제안하고 있다.

클라우드는 가상화된 저장 기술을 기반으로 신뢰성 있는 데이터 서비스를 추구하는 패러다임이라는 점에서 빅데이터 나 사물 인터넷과 구별되고, 빅데이터나 사물 인터넷을 지 원할 수 있는 하드웨어 및 운영체제 플랫폼 성격이 강하다.

위에서 살펴본 바와 같이, 사물 인터넷 데이터의 클라우 드 서비스 인터페이스를 위해 고려되어야 할 중요한 사항은 사물 인터넷 구성요소에 대한 접근 방법의 이질성과 데이터 포맷의 다양성에 대한 적응이 용이하고, 이들의 역동성을 지원할 수 있는 유연한 명명 서비스 기능이다.

\section{2 빅데이터 관련 도구 및 플랫폼}

현재 연구 혹은 상업용으로 가장 자주 활용되는 빅데이터 처리 도구로 MapReduce 기술[18]에 기반을 둔 Hadoop[19] 을 들 수 있는데, 이들은 대규모 데이터를 여러 노드에 분 산시켜 질의를 분산 - 병렬 처리하는 일종의 데이터베이스 인프라를 제공한다. 즉, 수집된 데이터를 대상으로 처리하므 로, 사물 인터넷 데이터의 다양성과 역동성, 그리고 유연한 명명 서비스와는 거리가 멀다. NoSQL[20]은 기존의 RDBMS 의 테이블 간 관계를 두지 않아 일관성 유지에 따른 성능 제한을 극복한다. 이로 인해 최소한의 성능 부담으로 분산 데이터베이스를 형성함으로써 대용량 데이터베이스를 지원 한다. 또한, 스키마를 고정시키지 않고 $\mathrm{key}^{-v}$ value 형태의 자 유로운 저장 형태를 취함으로써 사물 인터넷 데이터의 다양 성을 어느 정도 지원하는 것으로 볼 수 있지만, 일관된 서 비스 인터페이스 및 유연한 명명 서비스 기능과는 관계가 멀다.

기존 IT 벤더들의 관심이 가장 높은 분야가 클라우드 플 랫폼인데, 그 이유는 기존 서버 플랫폼의 클라우드 플랫폼 이전이 용이하기 때문이다. Azure(마이크로소프트)[21], AWS (아마존)[22], HP 등 유수의 IT 벤더들이 연합하여 공개 프 로젝트로 개발 중인 OpenStack[23] 등을 대표적인 사례로 들 수 있다. 이들 플랫폼들은 대용량이라는 슬로건 아래 확 장성, 신뢰성, 이식성, 저비용, 그리고 성능이라는 서버관념 수준에 머물러 아직까지 실질적인 사물 인터넷 특성들을 반 영하지 못하고 있다.

\section{3 파일 시스템}

일반적인 파일 시스템은 로컬 디스크에 디렉터리 체계 조 직을 위한 메타 정보와 사용자 데이터 저장을 위한 파일을 관리한다. 대표적인 예로 유닉스 파일 시스템, 윈도우 파일 시스템 등을 들 수 있는데, 거의 대부분 계층적 디렉터리 구조를 지원한다. 이들 로컬 파일 시스템을 네트워크를 통 해서 원격 시스템의 디렉터리 명칭 공간에 가상으로 연결하 면 NFS나 파일 서버와 같은 분산 파일 시스템으로 확장된 다. SAN(Storage Area Network)은 물리적인 저장 공간, 즉 디스크 공간을 로컬 시스템 버스가 아닌 네트워크로 연결하 는 방법으로 파일 시스템 조직에 대한 근본적인 변화는 없 다. 이러한 일반 파일 시스템, 분산 파일 시스템, SAN 등 기존의 파일 시스템 방법론들은 시스템에 도달한 데이터의
단순한 저장 기능을 주목적으로 하기 때문에 인터넷 구성요 소 자체에 대한 직접 접근, 즉 디바이스 파일에 대한 접근 지원은 지극히 제한적이다.

\section{$2.4 \mathrm{DB}$ 파일 시스템}

파일 시스템과 DBMS의 장 - 단점을 상호 보완하여 융합 시키는 시도를 $\mathrm{DB}$ 파일 시스템이라 한다. 마이크로소프트사 는 기존 파일 시스템의 단점으로 파일 유형 식별 한계와 파 일 검색 기능 미흡 등 두 가지를 지적하였다. 즉, 기존 파일 시스템에서는 파일 내용이 오로지 바이트 스트림으로만 인 식되므로 파일 내용 자체만으로는 어떤 애플리케이션의 파 일인지에 대한 식별이 불가능하고, 파일의 유형 또한 강제 할 수 없으므로 국제적으로 표준화된 애플리케이션에 의한 파일 공유에 한계가 있다는 것이고, 디렉터리 및 파일명만 이 유일한 검색 기준이어서 파일 유형별 관리에 한계가 있 다는 것이다. 이런 문제들을 해결하는 방안으로 파일의 구 성에 일정한 포맷을 적용하고, 이를 이용하여 파일의 명칭 과 유형, 그리고 파일 속성을 관리함으로써 “홍길동이 있는 사진”과 같은 파일 검색을 지원하는 새로운 패러다임의 $\mathrm{WinFS}$ (Window Future Storage)[24] 파일 시스템 개발을 시도하 였다. WinFS는 질의 기능 구현을 위해 파일 저장 구조에 관계형 $\mathrm{DB}$ 모델(SQLServer)을 도입했는데, 아직은 시기상 조라는 표현으로 2013년 실패를 자인하였다[25]. 오라클사는 대용량 $\mathrm{DB}$ 구축용 저장 공간 관리 기술을 파일 시스템에 접목하기 위해 DBFS(Database File System)[26]를 주창하 고 있는데, DBMS 위에 open()/read()/write()/close() 등 파 일 시스템 접근 인터페이스를 위한 $\mathrm{PL} / \mathrm{SQL}$ (저장 $\mathrm{SQL}$ 프로 시저)을 탑재하여 파일 시스템과 $\mathrm{DBMS}$ 의 양쪽 접근을 가 능하게 하면서, 내용이 동일한 파일들의 중복 제거(deduplication), 파일 압축(compression), 원자적 거래(atomic transaction) 처리, 읽기 일관성(read con-sistency) 등 DBMS 고유의 기능을 제공한다. $\mathrm{DBFS}$ 는 자체 성능 평가에서 순수 운영체제 파일 시스템과의 비교는 하지 않은 채, 일반적인 DBMS 성능 평가 관점에서 나쁘지 않다고 말하고 있다. 위 에서 살펴본 $\mathrm{WinFS}$ 와 $\mathrm{DBFS}$ 는 파일 자체를 관리하기 위한 커널 수준의 접근이고, 특정 벤더 중심의 폐쇄적 솔루션이 이서 무겁고 고비용이라는 공통점을 가지고 있다. 특히, $\mathrm{DBFS}$ 는 계층적 디렉터리 체계를 $\mathrm{DB}$ 에 관리한다는 측면에 서 본 연구와 개념이 동일하나 실제 파일을 조직한다는 점 에서 가상 파일 시스템이 아니고, 스키마 등 구체적인 내부 구현 내용에 관해서 알려진 바가 전혀 없으며, 파일 타입별 접근 루틴을 탑재할 수 있는 틀도 추구하지 않는다.

이 논문에서 구현하는 $\mathrm{DB}$ 기반 가상 파일 시스템은 Fig. 2 와 같이 분산된 사물 인터넷 구성요소들의 명칭, IP 주소, 위치, 타입 등의 속성 정보를 유닉스 파일 시스템 뷰와 동 일한 계층적 디렉터리 체계로 $\mathrm{DB}$ 에 관리하고, 각 타입별 접 근 프로시저들을 사용자 영역인 미들웨어 수준에서 포용함 으로써 커널 작업 및 특정 시스템 종속을 배제하고, $\mathrm{LDAP}$ 과 같은 기존의 독립된 명명 서버를 사용하지 않으면서도, 유연한 명명 관리 서비스와 일관된 접근 인터페이스를 원스 톱(one-stop) 환경으로 제공한다. 


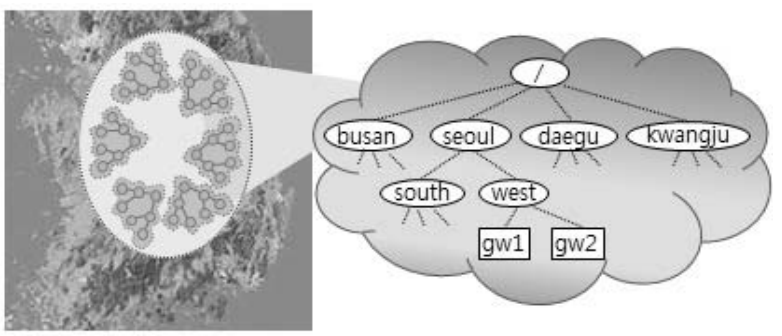

Fig. 2. Concept of the DB-based Virtual File System

\section{DB 기반 가상 파일 시스템 설계}

3.1 유닉스 파일 시스템

1) 파일과 inode

기본적인 유닉스 파일 시스템은 Fig. 3 과 같이 디스크의 물리적 저장 공간을 파일 타입과 소유자 등 파일의 속성 정 보를 저장하는 inode 영역과 파일 내용을 저장하는 데이터 영역으로 분리하고, 속성 정보의 하나로 데이터가 저장되어 있는 위치를 관리한다. 각 파일별로 할당되는 inode는 64 바 이트를 차지하며, 이들이 inode 영역에 배열 형태로 배치되 므로, 파일 시스템 전체적으로 모든 파일들은 각각 유일한 inode 번호를 부여받는 셈이다[27]. 즉, 유닉스 파일 시스템 은 파일을 생성할 때마다 Fig. 4와 같이 비어있는 inode 하 나를 할당하여 파일의 유일성을 확보한다.

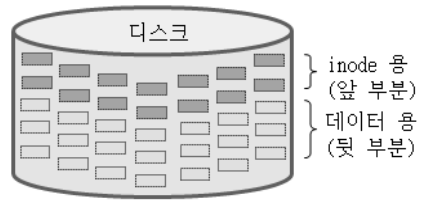

Fig. 3. Inode and Data Region of UNIX File System

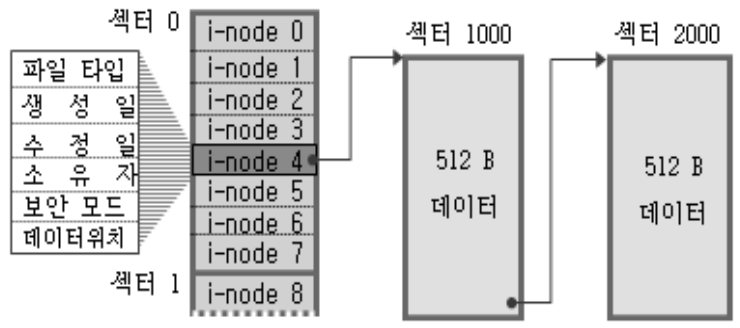

Fig. 4. Inode of UNIX File System

2) 파일과 디렉터리

유닉스 파일 시스템은 사용자 데이터를 저장하는 일반 파 일 외에 트리 형태의 디렉터리 체계를 구성하기 위한 디렉 터리 파일을 관리한다. 디렉터리 파일은 특수 파일 중의 하 나로, 생성되는 과정은 일반 파일과 동일하나 디렉터리 체 계 유지를 위한 정보를 저장하고, 사용자는 그 내용을 직접 편집할 수 없다. 디렉터리 파일의 구체적인 내용은 해당 디
렉터리 하부에 존재하는 자식 파일들에 대한 목록인데, 그 구성 형식은 Fig. 5에 보인 표 형태이다. 이 표로부터, 유닉 스 파일 시스템에서의 파일 이름은 속성 정보 영역인 inode 가 아니라 부모인 디렉터리 파일에 의해 관리되고 있음을 알 수 있다.

\begin{tabular}{|c|c|}
\hline i node 번호 & 파일 이름 \\
101 & test1.c \\
102 & test2.c \\
213 & report \\
\hline
\end{tabular}

Fig. 5. Data Format of a Directory File

3) 계층적 디렉터리 구조의 유지관리

초기화된 유닉스 파일 시스템은 최초의 파일인 루트 디렉 터리 하나를 갖게 되고, 이 디렉터리 파일은 보통 0 2번 inode에 할당한다. 디렉터리나 파일의 이름이 해당 파일을 연결하는 부모 디렉터리에 의해 관리되므로, 루트 디렉터리 는 임의의 이름을 가질 수 없고 "/”로 통일하여 사용된다. 이를테면 경로명 “/fname"은 루트 디렉터리에 연결된 "fname"을 의미하고, "fname"은 또 다른 디렉터리 파일이거 나 일반 파일일 수 있다. 루트 디렉터리에서 확장되어 계층 적 디렉터리가 형성되는 예를 Fig. 6에 보였고, 이러한 계층 적 디렉터리를 유지, 관리하기 위한 주요 프로시저는 아래와 같다[28].

- namei(char *pathname) : "/usr/.../fname" 형태의 경로 명에 대하여 Fig. 6의 계층적 디렉터리 파일 시스템으 로부터 최종 목적 파일인 “fname"에 대한 inode 번호 를 찾는다.

• mkdir(char *pathname) : "/usr/.../dir/dname" 형태의 경로명에 대하여 디렉터리 파일 "dir"의 inode를 찾은 후, 디렉터리 파일 하나를 생성하여 “dname" 이름으로 "dir" 디렉터리 파일의 엔트리에 등록한다.

• rmdir(char *pathname) : "/usr/.../dir/dname" 형태의 경로명에 대하여 디렉터리 파일 "dir"과 "dname"의 inode를 각각 찾은 후, 디렉터리 파일 “dname"을 삭제 하고, 디렉터리 파일 "dir"의 엔트리에서 "dname" 관련 내용을 제거한다.

• open (char *pathname, ...) : “/usr/.../dir/fname” 형태의 경로명에 대하여 디렉터리 파일 "dir"의 inode를 찾은 후, 일반 파일을 생성하여 "fname" 이름으로 "dir" 디렉 터리 파일의 엔트리에 등록한다(기존 파일 "fname"의 개방에도 사용됨)

• unlink(char *pathname) : "/usr/.../dir/fname" 형태의 경로명에 대하여 디렉터리 파일 “dir"과 일반 파일 "fname"의 inode를 각각 찾은 후, 일반 파일 "fname"을 삭제하고, 디렉터리 파일 "dir"의 엔트리에서 "fname" 관련 내용을 제거한다. 


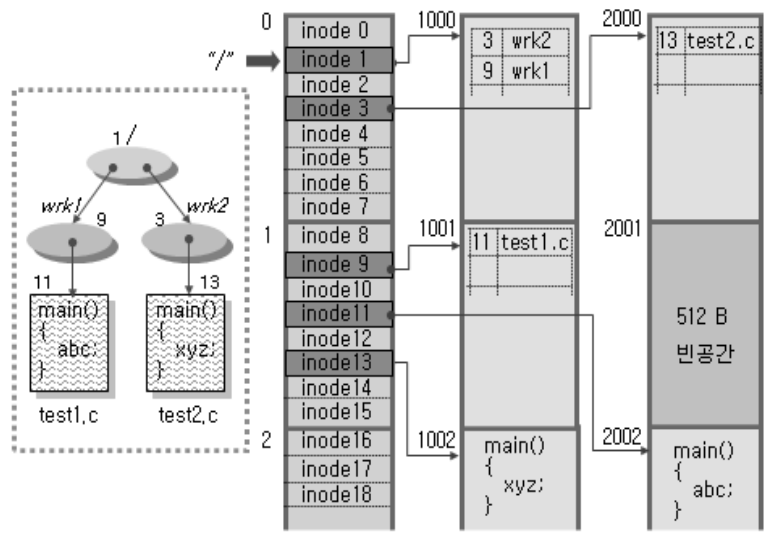

Fig. 6. Hierarchical Directory Structure of UNIX File System

\section{$3.2 \mathrm{DB}$ 기반 가상 파일 시스템 프레임}

Fig. 6의 예에서 계층적 디렉터리 체계 유지를 위한 핵심 정보는 디렉터리 파일인 “/”, "wrk1”, “wrk2” 등 세 개의 파 일에 의해 관리되고 있다. 본 가상 파일 시스템의 목적은 이들 디렉터리 파일의 내용을 $\mathrm{DB}$ 에 관리하고, 일반 파일 "test1.c"와 "test2.c"에 대해서는 해당 파일이 실제 존재하는 위치에 대한 지시자만 관리하는 데 있다. 이들 일반 파일에 대한 유형은 $\mathrm{USN}$ 실시간 게이트웨이 데이터, $\mathrm{USN} \mathrm{DB}$, 일 반 유닉스 파일 등 사물 인터넷 구성요소의 형태에 따라 설 정한다. 즉, 모니터링, 데이터 분석, 데이터 수집 등의 응용 프로그램이 Fig. 7과 같이 가상 파일 시스템 미들웨어 API vfs_open()을 호출하면, vfs_open()이 DB로부터 계층적 디 렉터리 체계를 따르는 경로명을 파악하여 최종 단말 파일의 inode 정보를 추출한 후, 해당 파일의 유형에 따른 데이터 접근 세션을 개설하고, 이후 vfs_read(), vfs_write() API가 이어질 수 있는 데이터 구조를 준비한다.

새로운 접근 유형을 필요로 하는 사물 인터넷 구성요소에 대한 지원이 필요한 경우, 새로운 파일 타입과 함께 미들웨 어 내부에 대응되는 접근 프로시저를 삽입함으로써 응용 프 로그램에 일관된 유닉스 파일 시스템 인터페이스 뷰를 제공 한다. 또한, 디렉터리나 파일의 생성 - 이동 - 삭제 - 명칭 변 경 등이 mkdir 등 유닉스 셀 명령어 형태로 이루어지므로 명칭의 검색 및 관리가 용이하다.

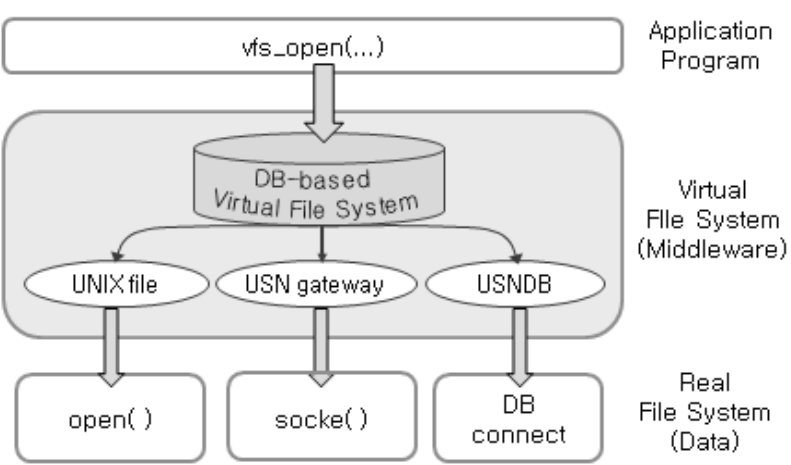

Fig. 7. Frame of the DB-based Virtual File System

\section{$3.3 \mathrm{DB}$ 기반 가상 파일 시스템 설계}

유닉스 파일의 주요 속성 정보는 소유자, 소유자 그룹, 생 성 시간, 그리고 inode 번호이다. 이를 위해서 "/etc/group" (사용자 그룹 id), "/etc/passwd"(사용자 id)에 대응되는 테 이블을 두고, 디렉터리 테이블이 이들 두 테이블을 참조하 도록 한다.

'vgroup'과 'vuser' 테이블

'group' 테이블은 문자열 타입의 그룹 명칭과 정수 타입 의 그룹 id 필드로 구성되어, 이 중에서 그룹 id는 키 역할 과 함께 'vuser' 테이블에서 참조된다. 'vuser' 테이블은 문자 열 타입의 사용자 명칭(로그인 id) 및 패스워드, 정수 타입의 사용자 id 및 그룹 id, 그리고 문자열 타입의 home으로 구성 되어, 사용자 id가 키로서 디렉터리 테이블에서 참조된다. 'vgroup' 및 'vuser' 테이블 필드 내용을 Table 1에 보였다.

Table 1. Field Design of the 'vgroup' and 'vuser' Table

\begin{tabular}{c|c}
\hline \multicolumn{2}{|c}{ 'vgroup' } \\
\hline 필 드 & 타 입 \\
\hline gname & 문자열 \\
\hline gid & 정수(키) \\
\hline
\end{tabular}

\begin{tabular}{c|c}
\hline \multicolumn{2}{|c}{ 'vuser' } \\
\hline 필 드 & 타 입 \\
\hline name & 문자열 \\
\hline pass & 문자열 \\
\hline uid & 정수(키) \\
\hline gid & 정 수 \\
\hline home & 문자열 \\
\hline
\end{tabular}

'vfs' 테이블

'vfs' 테이블은 유닉스 파일 시스템의 디렉터리 파일 내용 을 저장한다. 모든 디렉터리 파일의 엔트리를 기록하되, 부 모-자식 inode 관계에 의해 특정 디렉터리의 엔트리(하부 파일 및 디렉터리)를 검색할 수 있도록 한다. 이를테면, Fig. 6의 예에서 “/”루트) 디렉터리의 “wrk1"와 “wrk2" 엔트리 는 $(1,9)$ 와 $(1,3)$ 으로 각각 식별되고, 이들은 부모 inode가 1 인 레코드 조건에 의해 검색된다. 즉, 특정 디렉터리의 엔 트리들은 그 디렉터리의 inode를 부모로 가질 조건으로 검 색할 수 있다. 또한, 디렉터리 명칭 “””(해당 엔트리를 포함

Table 2. Field Design of the 'vfs' Table

\begin{tabular}{|c|c|c|}
\hline 필 드 & 타 입 & 내 용 \\
\hline inode & 정 수 & 디렉터리별 부여 번호 \\
\hline pinode & 정 수 & 부모 inode 번호(키 파트1) \\
\hline name & 문자열 & 엔트리(하부 파일 혹은 디렉터리) 명칭(키 파트2) \\
\hline uid & 정 수 & 소유자 id('vuser' 테이블 참조) \\
\hline gid & 정 수 & 소유자 그룹 id('vgroup' 테이블 참조) \\
\hline type & 자 & 디렉터리 혹은 사물 인터넷 파일 유형 \\
\hline iotfd & 문 자 & 사물 인터넷 데이터 지시자 \\
\hline
\end{tabular}


하고 있는 디렉터리)과 “..”(해당 엔트리를 포함하고 있는 부 모 디렉터리)의 존재로 인하여, 이 테이블에서 각 레코드는 inode 하나에 의해서는 유일하게 식별될 수 없고, <부모 inode, 엔트리 명칭>의 조합에 의해 유일하게 식별된다. Table 2에 'vfs' 테이블의 필드 내용을 보였다.

\section{DB 기반 가상 파일 시스템 구현 및 검증}

\subsection{DB 구현}

\section{개발 환경 및 $\mathrm{DB}$ 스키마}

Table 3 의 개발 환경에서 Table 1, 2의 테이블 생성을 위 한 SQL문을 Fig. 8에 보였고, 여기서 'inode_seq' 테이블은 inode 번호 발생기 용도이다.

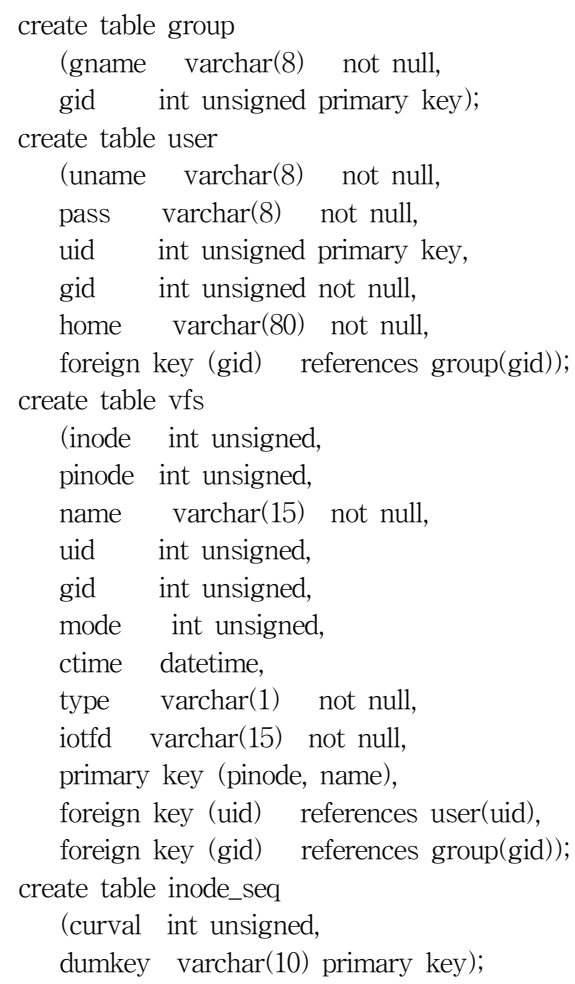

Fig. 8. SQL for DB Schema of the Virtual File System

Table 3. Development Environment

\begin{tabular}{c|ccc}
\hline 구 분 & 사 양 & 구 분 & 사 양 \\
\hline 운영체제 & Window 7 & 개발도구 & $\begin{array}{c}\text { Visual Studio } \\
2010\end{array}$ \\
\hline DBMS & MySQL 5.6 & 개발언어 & $\mathrm{C}$ \\
\hline
\end{tabular}

- 'vfs' 테이블 초기화 파일 시스템을 초기화(포맷)하면 두 개의 엔트리 “"”와 “..”를 가진 루트 디렉터리가 생성된다. 본 가상 파일 시스템 에서는 루트 디렉터리 inode를 1번, 부모 디렉터리 inode를 0 번으로 지정하여 두 엔트리를 삽입하여 초기화한다.

\section{2 파일 시스템 인터페이스 프로시저(미들웨어 API) 구현}

•vfs_namei(): 주어진 경로명상의 단말 파일이나 디렉터 리에 대한 inode 번호, 파일명, 파일 타입, 그리고 사물 인터 넷 데이터 지시자를 탐색한다. 이를테면 경로명이 “/USN/ seoul/west/gw1"이라면 계층적 디렉터리 체계를 탐색하여 말단 파일 "gw1"에 대한 부모 inode(pinode), 자식 inode (cinode), 파일명(cfname), 파일 지시자(iotfd) 등을 검색한다 (Fig. 9의 의사코드 참조. 이하 모든 의사코드에서 uid, mode, datetime 등의 기타 속성들은 생략되었음).

procedure integer vfs_namei(in string path, out integer pinode, out integer cinode, out string cfname, out string ctype, out string iotfd) \{

string ctoken;

cfname $=$ get_next_token_from_path(path)

if (cfname $\neq$ "/") return FAIL;

pinode $=0$, cinode $=1$, type $=$ "d", iotfd $=$ "”;

do \{

ctoken = get_next_token_from_path $($ path $) ;$

if (ctoken $==$ NULL) return SUCCESS:

pinode $=$ cinode, cfnam $\mathrm{e}=$ ctoken;

cinode $=$ db_get_dir_entry $($ pinode, ctoken, ctype, iotfd $)$;

\} while(cinode $\neq$ INVALID);

return FAILURE;

\}

MYSQL_RES *sql_result;

MYSQL_ROW sql_row;

procedure integer db_get_dir_entry(in integer flag, in integer pinode, in string cfname, out string ctype, out string iotfd) \{

string query;

integer cinode;

sprintf(query, "select inode, type, iotfd from vfs where pinode $=\% \mathrm{~d}$ and name $=$ " $\% \mathrm{~s}$ ', pinode, cfname);

if (mysql_query(dbid, query) != 0) return INVALID; sql_result = my_sql_store_result(dbid); sql_row = my_sql_fetch_row $($ sql_result $)$; if (sql_row == NULL) return INVALID; cinode = atoi $($ sql_row $[0])$;

ctype $=$ sql_row $[1]$;

iotfd = sql_row[2];

return cinode;

\}

Fig. 9. Pseudo Code for the vfs_namei() Procedure 


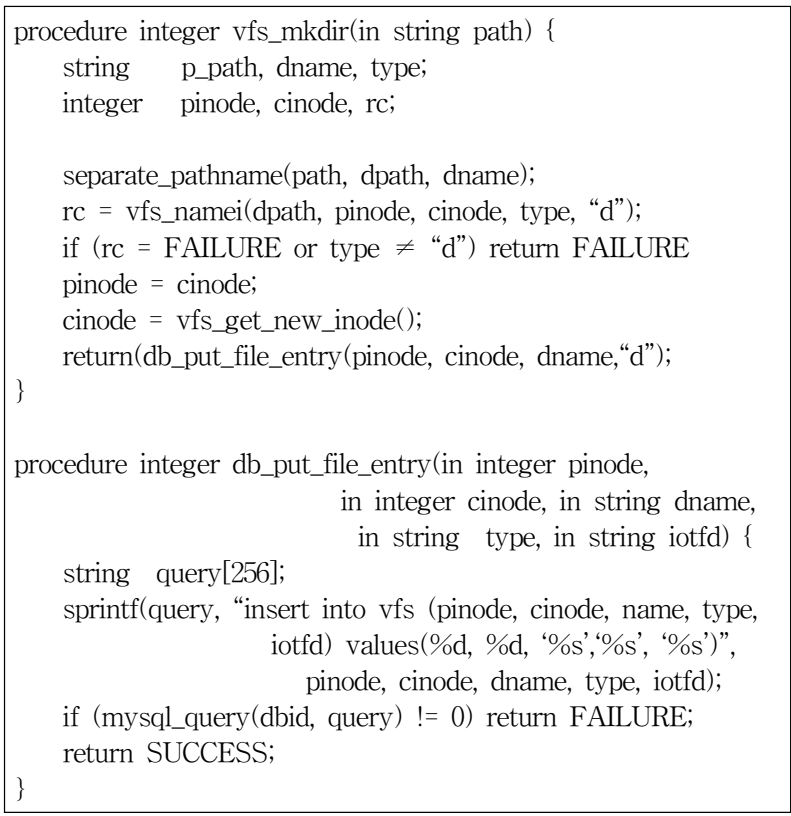

Fig. 10. Pseudo Code for the vfs_mkdir() Procedure

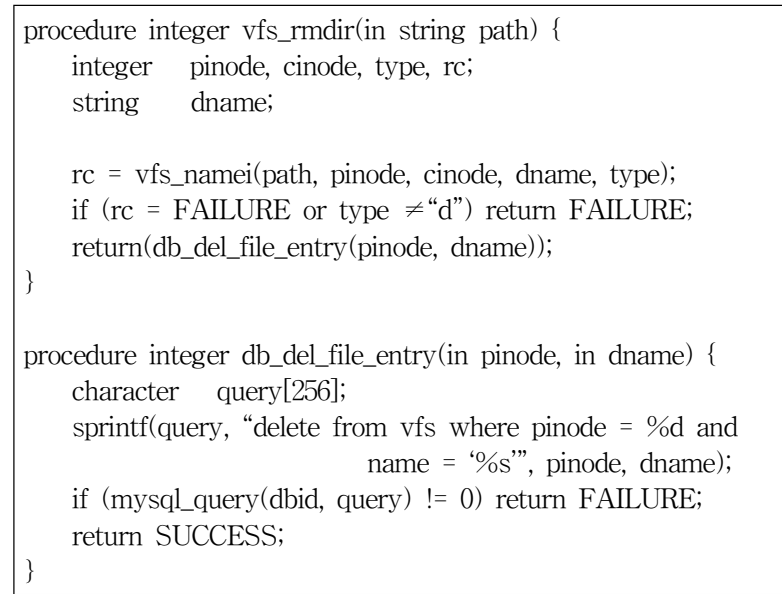

Fig. 11. Pseudo Code for the vfs_rmdir() Procedure

•vfs_mkdir(): 디렉터리를 생성하는 프로시저로서, “/USN /seoul/north" 형태로 주어진 경로명으로부터 기존 디렉터리 경로명 “/USN/seoul”(=dpath)과 생성하고자 하는 디렉터리 명 “north”(=danme)를 분리한 다음, vfs_namei() 프로시저를 이용하여 dpath의 inode 번호를 찾고(=pinode), 새로운 inode 번호(=cinode)를 발급받아 <pinode, cinode, dname, "d"> 튜 플의 디렉터리 엔트리를 "vfs" 테이블에 삽입한다(Fig. 10 의사코드 참조).

- vfs_rmdir(): 디렉터리를 제거하는 프로시저로서 “/USN /seoul/north" 형태로 주어진 경로명으로부터 vfs_namei() 프로시저를 이용하여 삭제하려는 디렉터리 "north"(dname) 의 부모 inode 번호(=pinode)를 검색하여 <pinode, dname> 튜플을 삭제한다(Fig. 11 의사코드 참조).

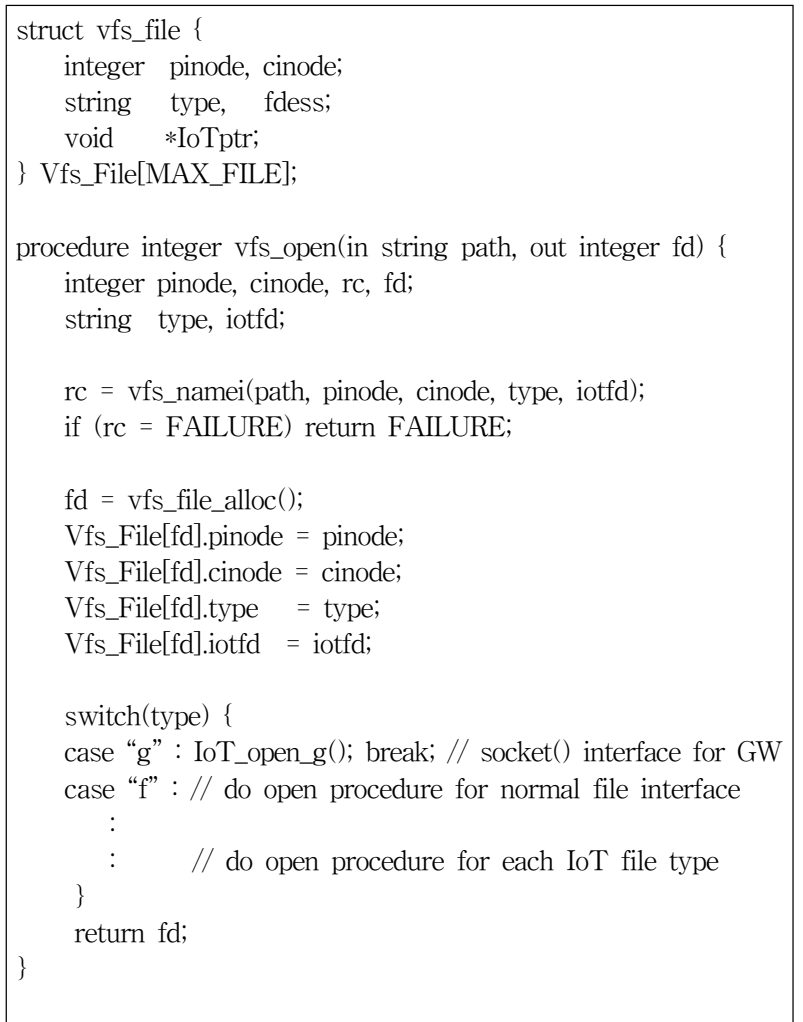

Fig. 12. Pseudo Code for the vfs_open() Procedure

- vfs_mkiot(): 사물 인터넷 구성요소를 기술하는 단말 파 일을 생성하는 프로시저로서 $v f s \_m k d i r()$ 과 동일하나, 파일 기술자(iotfd)와 디렉터리가 아닌 사물 인터넷 파일 타입을 필요로 한다.

- vfs_rmiot(): 사물 인터넷 구성요소를 기술하는 단말 파 일을 삭제하는 프로시저로서 vfs_rmdir()과 유사하다.

•vfs_open(): vfs_namei()를 이용하여 주어진 경로명에 대응되는 파일의 속성 정보를 얻은 후, 사물 인터넷 파일 타입에 대응되는 개방 절차를 진행한 결과를 vfs_file 구조 $\mathrm{fd}$ 에 기록하고, $\mathrm{fd}$ 를 반환한다. Fig. 12 는 vfs_open()의 의사 코드이다.

-vfs_read(), vfs_write(): vfs_open()에서 개방된 사물 인 터넷 파일에 대한 타입별 입 - 출력 서비스를 제공한다.

- vfs_chdir(): vfs_namei()를 이용하여 주어진 작업 디렉 터리 경로명의 유효성을 확인한 후, 사용자의 현재 작업 디 렉터리를 새롭게 설정한다.

\section{3 디렉터리 캐시 구현}

$\mathrm{DB}$ 기반 가상 파일 시스템은 운영 및 관리적인 측면에서 매우 효율적이나, 성능 관점에서는 미흡할 수 있다. 이를 보 완하기 위해 Fig. 13과 같은 해시 테이블을 이용한 간단한 디렉터리 캐시 기법을 도입한다. 


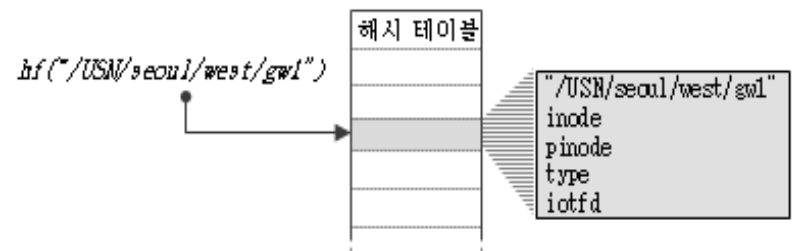

Fig. 13. Directory Cache Mechanism for the Virtual File System

해싱 함수

파일 및 디렉터리명에 허용되는 문자 집합의 크기를 숫자 10 개, 알파벳 대-소문자 52 개, 기호문자 2 개 등 총 64 개로 설정하고, 주어진 경로명의 끝 3 문자를 64 진법 정수로 변 환한 다음 해시 테이블 사이즈로 나누는 모드 연산 결과를 해시 값으로 사용한다. 충돌이 일어난 경우, 해당 위치로부 터 빈 곳을 선형으로 검색하여 삽입한다.

캐시 운영 정책

이 연구는 사물 인터넷 파일 1000 개 정도의 중규모 클라 우드를 목표로 하여 내용물이 크지 않으므로(약 $2 \mathrm{M}$ ), 완전 캐싱 정책을 채택하고, 시스템 부팅 시에 캐시를 형성한다. 이후, 디렉터리 생성-삭제, 사물 인터넷 파일 생성-삭제 등 변경 사항이 있는 경우 write-through 방식으로 처리한다.

\section{4 가상 쉘 유틸리티 구현}

제안된 가상 파일 시스템에 대한 사용자들의 운용을 지원 하기 위해 파일 시스템 인터페이스 프로시저를 토대로 구현 한 가상 쉘 유틸리티(기본 명령어)들은 Table 4와 같다.

Table 4. Virtual Shell Utilities for the Virtual File System

\begin{tabular}{|c|c|c|c|}
\hline 명령어 & 기 능(용 도) & 명령어 & 능(용 \\
\hline \multirow{2}{*}{ vsh } & \multirow{2}{*}{$\begin{array}{l}\text { 로그인 및 가상 파일 } \\
\text { 시스템 명령어 처리 }\end{array}$} & vmkiot & 사물 인터넷 파일 생성 \\
\hline & & vrmiot & 사물 인터넷 파일 삭제 \\
\hline ved & 작업 디렉터리 이동 & vfind & 파일 시스템 경로명 탐색 \\
\hline vls & 파일 탐색 & vformat & 파일 시스템 초기화 \\
\hline vmkdir & 디렉터리 생성 & vaddgrp & 파일 시스템 그룹 등록 \\
\hline vrmdir & 디렉터리 삭제 & vaddusr & 파일 시스템 사용자 등록 \\
\hline
\end{tabular}

4.5 가상 파일 시스템 기능 검증

Table 4의 가상 쉘 유틸리티들을 사용하여 가상 파일 시스템의 초기화부터 파일 시스템의 확장 및 축소 등 운 용 과정을 보임으로써 구현된 가상 파일 시스템의 기본 기 능을 검증한다.

파일 시스템 초기화

초기화 명령어 vformat은 Fig. 14와 같이, 'system'과 'root'를 기본 그룹과 사용자로 등록하고('vgroup' 및 'vuser' 테이블), 파일 시스템(“vfsr' 테이블)에 “/”(루트) 디렉터리를 생성한다.

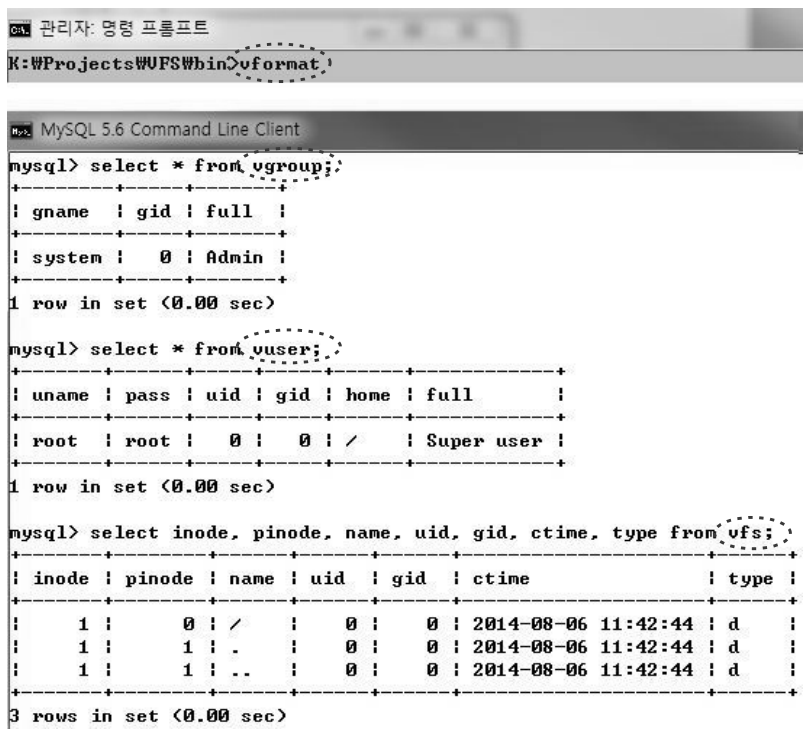

Fig. 14. File System Initialization by the vformat Command

사용자 계정 등록

Fig. 15는 vmkdir 명령어에 의한 사용자 홈 디렉터리 “/usr/home/lee"의 생성, vaddgrp•vaddusr 명령어에 의한 그룹 "iot" 및 사용자 "lee"를 등록하는 모습을 보이고 있다.

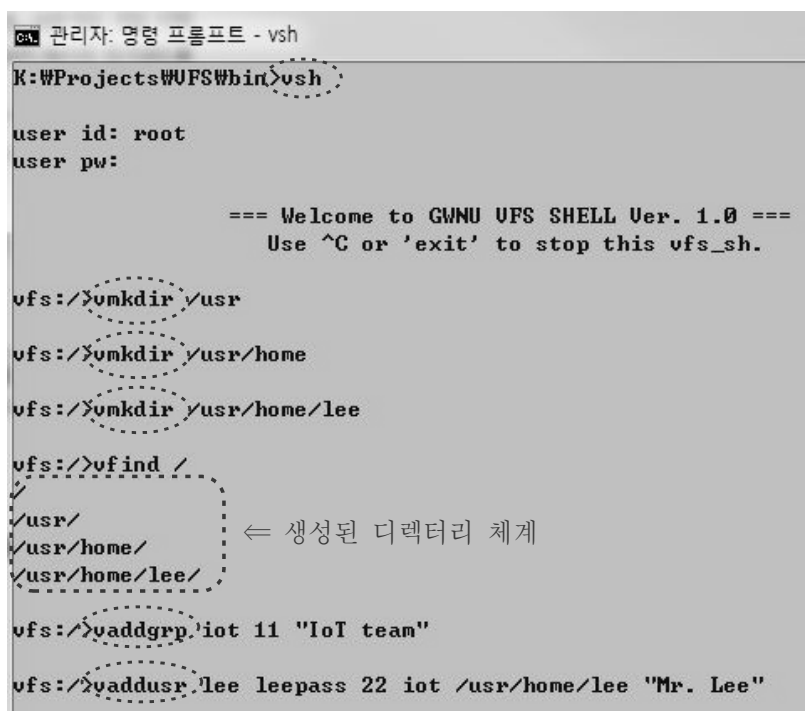

Fig. 15. Process of a User Account Creation

사용자 계정 로그인 및 파일 시스템 운용

관리자 및 일반 사용자들은 vmkdir, vrmdir, vmkiot, vrmiot 명령어를 사용하여 디렉터리 체계와 파일을 자유롭 게 생성하거나 삭제할 수 있다. Fig. 16에 일반 사용자 'lee' 가 로그인하여 세 가지 유형(USN 게이트웨이, USN DB, 일 반 파일)의 사물 인터넷 파일을 생성하고 삭제하는 과정을 보였다. 여기서 보인 사물 인터넷 파일의 유형들은 예시이 고, 미들웨어 내부 정의 및 구현에 의해 추가되거나 확장될 수 있다. 


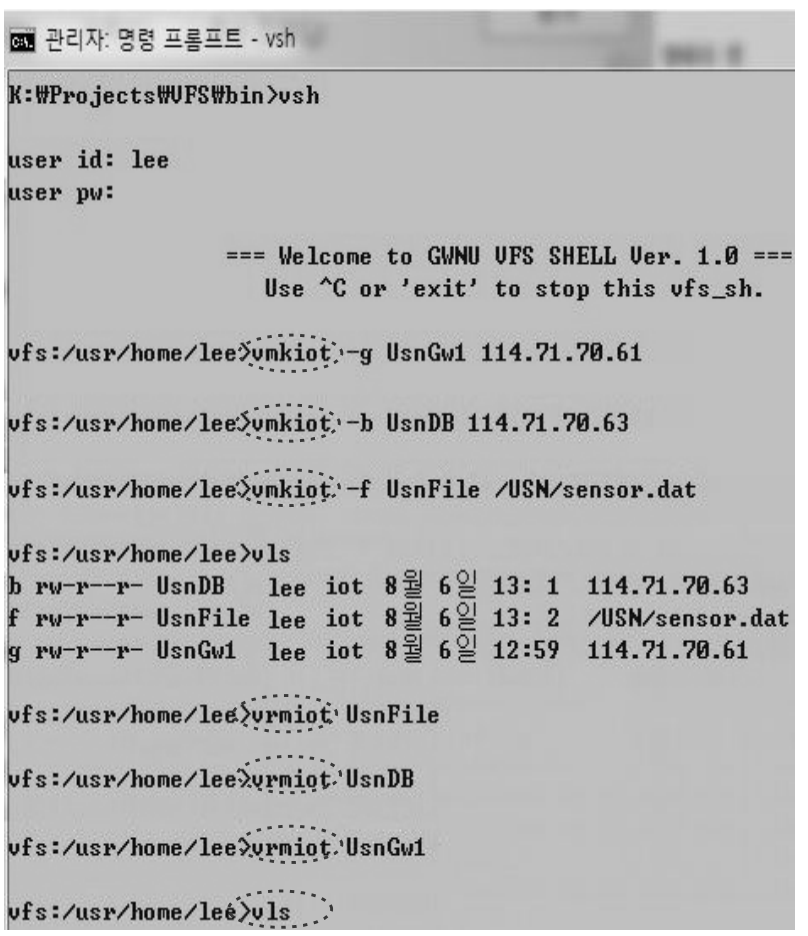

Fig. 16. File System Manipulation by a End User

사물 인터넷 디바이스 접속

구현 가상 파일 시스템을 통한 사물 인터넷 디바이스 접 속메커니즘을 검증하기 위해, USN 싱크노드와 시리얼 통신 으로 연결된 Fig. 16의 "UsnGw1"(USN 게이트웨이)로부터 온도와 습도를 현재 시각과 함께 실시간으로 수신하는 응용

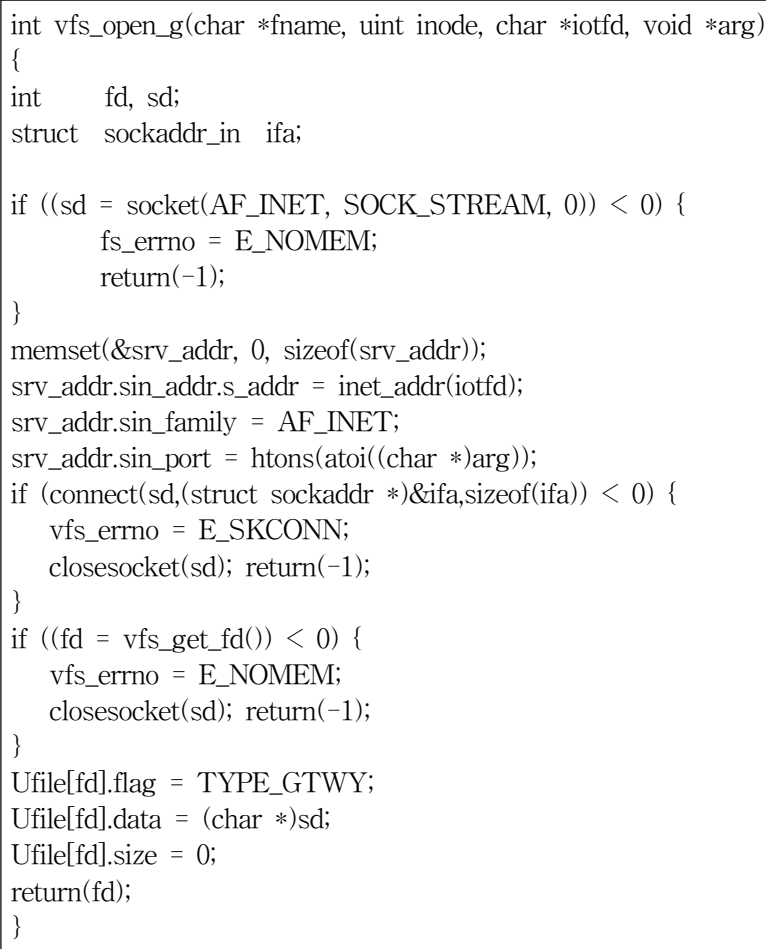

Fig. 17. C Code for the loT_open_g() Procedure

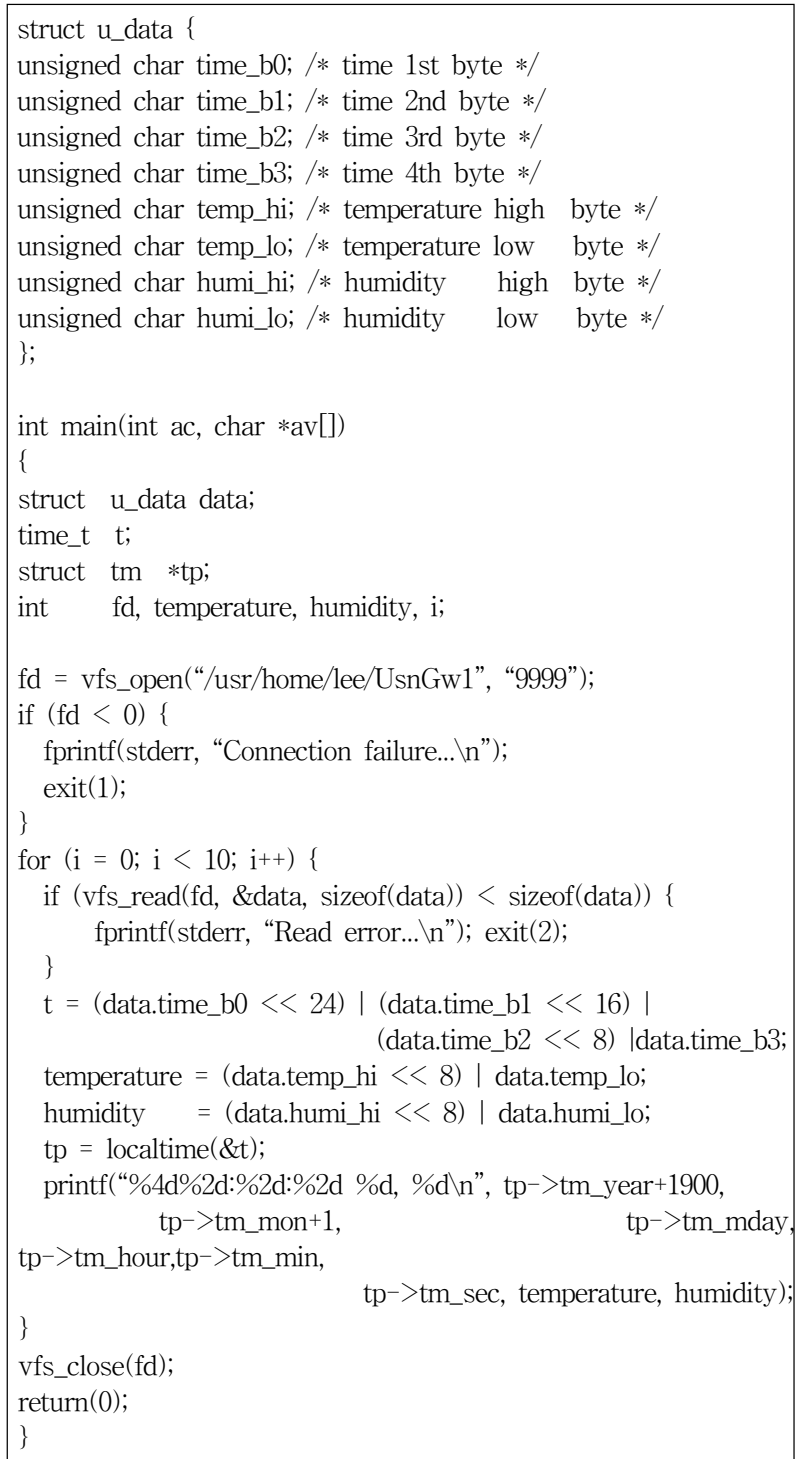

Fig. 18. C Code for an IoT Cloud Application('gateway')

프로그램을 구동시켜 시험한다. 이를 위한 Fig. 12의 파일 타입 "g"의 접근 프로시저 IoT_open_g() 프로시저와 응용 프로그램의 C 언어 코드는 각각 Fig. 17, Fig. 18과 같다. 본 가상 파일 시스템이 관리하는 모든 IoT 파일은 Fig. 18의 예와 같이 vfs_open() 프로시저로 접근할 수 있고, Fig. 19 는 이 응용 프로그램의 성공적인 실행 결과를 보이고 있다.

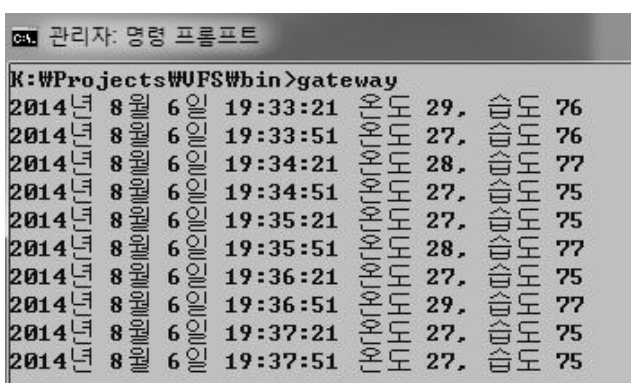

Fig. 19. Screen Shot of the 'gateway' Application 


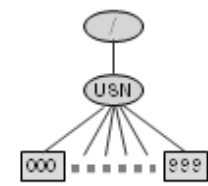

(a) depth-1

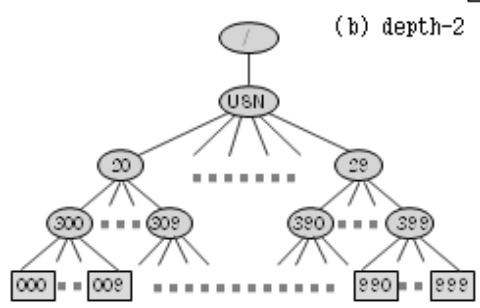

(c) depth-3

Fig. २०. Experimental Design of the VFS Performance Evaluation

\section{6 가상 파일 시스템 성능 평가}

가상 파일 시스템의 성능에 대한 우려를 검증하는 평가를 위해 실제 상황과 동일하게 1000 개의 단말 파일을 Fig. 20 과 같이 1 단(depth-1), 2단(depth-2), 3단(depth-3) 등 세 가 지의 디렉터리 체계로 생성하고 탐색하는 시간(순수한 $\mathrm{CPU}$ 실행 시간이 아닌 대기 시간 포함)을 $\mathrm{NTFS}$ (윈도우 파일 시 스템)와 $\operatorname{VFS}$ (구현 가상 파일 시스템)에서 측정하되, 디렉터 리 및 파일명의 길이를 5(length-5), 10(length-10), 15 (length-15)로 변화를 주었다. 주어진 분석 데이터는 각 경 우에 대한 5 회 실험 결과의 평균이다.

디렉터리 생성 성능

Table 5, 6에 3단 디렉터리 경우의 길이별 생성 시간과, 파일명 길이 15 인 경우의 깊이(단)별 생성 시간을 비교해보 였다. 이 결과로부터 어느 쪽이나 파일명 길이에 따른 뚜렷 한 차이는 존재하지 않고, VFS의 경우 깊이에 따라 약 $20 \%$ 정의 정도의 소요시간이 증가함을 볼 수 있다. 두 파일 시 스템 간의 큰 성능 차이는 예견된 결과로서, NTFS의 경우 운영체제에서 관리되는 디스크 버퍼 캐시 메커니즘에 의해 일차적으로 메모리 입·출력이 적용되는 반면, $\mathrm{VFS}$ 의 경우 에는 $\mathrm{DB}$ 본연의 로그 기록 등 실질적인 디스크 입·출력을 필요로 하기 때문이다. 그러나 $\mathrm{VFS}$ 는 전형적인 읽기 지향 적 환경에서 운영되므로 생성 시간의 단점은 크게 문제되지 않는다.
Table 5. Creation Time of Depth-3 Case(unit: ms)

\begin{tabular}{c|c|c}
\hline FS 유형 & NTFS & VFS \\
\hline leng이 & & \\
\hline length-10 & 222 & 74011 \\
\hline lenght-15 & 222 & 74698 \\
\hline
\end{tabular}

Table 6. Creation Time of Length-15 Case(unit: ms)

\begin{tabular}{c|c|c}
\hline 깊이 & NTFS & VFS \\
\hline depth-1 & 185 & 54458 \\
\hline depth-2 & 187 & 65192 \\
\hline depth-3 & 229 & 73236 \\
\hline
\end{tabular}

디렉터리 탐색 성능

Table 7,8 에 생성 시간 측정과 동일한 방법으로 1000 개 의 단말 파일에 대한 탐색(개방) 시간 측정 결과를 보였 다. 이들 표에서 $\mathrm{VFSc}$ 는 $\mathrm{VFS}$ 에 약 $2 \mathrm{M}$ 바이트의 캐시를 적용한 경우이다. 생성 성능에서와 마찬가지로 탐색 성능 에서도 어느 쪽이나 파일명 길이에 따른 영향은 거의 없 고, $\mathrm{VFS}$ 및 $\mathrm{VFSc}$ 의 경우 깊이에 따라 소요 시간이 증 가함을 볼 수 있다. 캐시를 사용하지 않은 VFS의 탐색 시간은 NTFS에 비해 약 7 8배 정도 느리지만, 캐시를 사용한 $\mathrm{VFSc}$ 의 경우는 2 배 이상 빠르다. 이 결과는, $\mathrm{NTFS}$ 와 VFSc 모두 캐시에 의한 메모리 참조를 하지만 NTFS의 경우 운영체제 시스템 호출 부담과 캐시 정책의 복잡성으로 인해 사용자 영역에서 운영되는 간결한 VFSc 보다 성능이 저조한 것으로 분석된다. 업데이트 질의가 거 의 없는 $\mathrm{VFS}$ 에 대한 캐시의 적용은 아주 적절한 정책으로 볼 수 있다.

Table 7. Exploration Time of Table 8. Exploration Time of Depth-3 Case(unit: ms)

\begin{tabular}{|c|c|c|c|c|c|c|c|}
\hline & & & & & & & \\
\hline 길이 $F S$ 유형 & NTFS & VFS & VFSc & 길이 & NTFS & VFS & VFSc \\
\hline length -5 & 96 & 775 & 39 & depth-1 & 88 & 551 & 2 \\
\hline length-10 & 91 & 770 & 41 & depth-2 & 90 & 576 & 17 \\
\hline lenght-15 & 91 & 784 & 41 & depth-3 & 91 & 784 & 41 \\
\hline
\end{tabular}

\section{5. 결론 및 향후 계획}

이 연구에서는 사물 인터넷을 구성하는 다양한 형태의 요 소들을 통합된 디렉터리 명칭 공간 내에 포용하여, 일관된 뷰에 의한 탐색과 접근이 가능한 $\mathrm{PaaS}$ 형 클라우드 서비스 플랫폼의 하나로 $\mathrm{DB}$ 기반 가상 파일 시스템을 구현하고 검 증하였다. 구현된 가상 파일 시스템은 운영체제 커널이 아 닌 사용자 영역의 미들웨어 수준에서 트리 구조의 디렉터리 체계를 $\mathrm{DB}$ 에 관리하므로 유지, 관리가 용이할 뿐 아니라, 유닉스와 동일한 가상 쉘 환경을 제공하기 때문에 사용자들 과의 친밀도가 높다. 또한, 구현 가상 파일 시스템에서는 별 도의 명명 서비스가 필요하지 않다. USN 게이트웨이 1000 개 정도로 구성된 중규모 사물 인터넷 클라우드를 목표로 기능과 성능을 평가한 결과 충분히 만족스러운 결과를 얻을 수 있었다. 향후 이어지는 연구에서는 보안모드의 적용으로 파일 시스템을 완성하고, 사물 인터넷 구성요소들의 전형적 인 유형 도출 및 이들에 대한 기본 접근 인터페이스 프로시 저 개발이 이루어질 예정이다. 


\section{References}

[1] Howon Kim, Dong Kyue, "Technology and Security of IoT", Journal of The Korea Institute of Information Security and Cryptology, Vol.22, No.1, pp.7-13, 2012.

[2] Man-Mo Kang, Sang-Rak Kim, "The Emerging Fusion ServiceT", Communications of the Korean Institute of Information Scientists, Vol.32, No.2, pp.9-21, 2014.

[3] Darren Quick, Kim-Kwang Raymond Choo, "Dropbox analysis: Data remnants on user machines", Digital Investigation, Vol.10, No.1, pp.3-18, 2013.

[4] Peter Mell, Timothy Grance, "The NIST Definition of the National Institute of Standards and Technology", NIST Special Publication(800-145), p.7, 2011.

[5] Su-Mi Shin, Mi-Whan Hyun, and Hae-Sun Kim, "Trends and Cases of Cloud-based Information Service", Knowledge Report of KISTI, No.39, pp.8-14, 2013.

[6] Park So Yeon, Kim Yongwon, "An Analysis of the Interaction Effect of Benefit and", KIPS Transactions on Computer and Communications Systems, Vol.2, No.1, pp.27-34, 2013.

[7] Hyung-Bong Lee, "Design of a DB-based Virtual File System for Lightweight Clouding", in Proceedings of the 2014 Spring Conference of the KIPS, Vol.21, No.1, pp.81-82, 2014.

[8] Ho-Jin Park, Yeong-Hun Kwon, and Yeong-Min Ahn, "Big Data and Big Data Refinement Technology", KSCI review, Vol.21 No.1, pp.1-8, 2013.

[9] James Manyika, Michael Chui et al., "Big data: The next frontier for innovation, competition, and productivity", McKinsey Global Institute, 2011(http://www.mckinsey. com/insights/business_technology/big_data_the_next_fronti er_for_innovation).

[10] Laney Douglas, "3D Data Management: Controlling Data Volume, Velocity and Variety", Application Delivery Strategies(Meta Group(Gartner)), 2001(http://blogs.gartner. com/doug-laney/files/2012/01/ad949-3D-Data-Manage ment-Controlling-Data-Volume-Velocity-and-Variety . pdf).

[11] Tae-hun Kim, Junghan Kim, and Young Ik Eom, "A Scheme on High-Performance Caching and High-Capacity File Transmission for Cloud Storage Optimization”, The Journal of Korea Information and Communications Society, Vol.37C, No.8, pp.670-679, 2012.

[12] Young Chang Kim, Dong Oh Kim et al., "MAHA-FS: A Distributed File System for High Performance Metadata Processing and Random IO", KIPS Transactions on Software and Data Engineering, Vol.2, No.2, pp.91-96, 2013.
[13] Hyunjean Choi, Ki Yong Lee, "Efficient Processing of an Aggregate Query Stream in MapReduce”, KIPS Transactions on Software and Data Engineering, Vol.3, No.2, pp.73-80, 2014.

[14] Hyoungrae Kim, Do-hong Jeon, and Sunghyun Jee, "Bigdata Analysis Project Development Methodology", Journal of The Korea Society of Computer and Information, Vol.19, No.3, pp.73-85, 2014.

[15] Boyi Xu, Li Da Xu et al., "Ubiquitous Data Accessing Method in IoT-Based Information System for Emergency Medical Services", IEEE Transactions on Industrial Informatics, Vol.10, No.2, pp.1578-1586, 2014.

[16] Kyeong-Seob Kwak, "IoT and Software Tasks", Communications of the Korean Institute of Information Scientists, Vol.32, No.6, pp.9-18, 2014.

[17] Chi Harold Liu, Bo Yang, and Tiancheng Liu, "Efficient naming, addressing and profile services in Internet-ofThings sensory environments", Ad Hoc Networks, Vol.18, pp.85-101, 2014.

[18] J. Dean, S. Ghemawt, "MapReduce: simplified data processing on large clusters", Communications of ACM, Vol.51, No.1, pp.107-113, 2008.

[19] Apache projects, Hadoop, http://Hadoop.apache.org, accessed at 1st Aug., 2014.

[20] Dr. S. George, "NOSQL - NOTONLY SQL," International Journal of Enterprise Computing and Business Systems, Vol.2, Issue 2, 2013.

[21] Microsoft Azure, http://azure.microsoft.com/ko-kr/, accessed at 1st Aug., 2014.

[22] Amazon AWS, http://aws.amazon.com/ko/, accessed at 1st Aug., 2014.

[23] OpenStack community, http://www.openstack.org/, accessed at 1st Aug., 2014.

[24] Richard Grimes, "Revolutionary File Storage System Lets Users Search and Manage Files Based on Content”, MSDN Megazine, 2004(http://msdn.microsoft.com/en-us/magazine/ cc164028.aspx).

[25] Mary Jo Foley, "Bill Gates' biggest Microsoft product regret: WinFS”, ZDNet, 2013(http://www.zdnet.com/bill-gates-biggestmicrosoft-product-regret-winfs-7000011136).

[26] Krishna Kunchithapadam, Wei Zhang, et al., "DBFS and SecureFiles", Oracle Corporation Technical Article, 2011 (http://www.oracle.com/technetwork/database/features/ secure-files/dbfs-benchmark-367122.pdf).

[27] Hyung-Bong Lee, "UNIX Fundamental for Developers", Human Science, pp.396-403, 2012.

[28] Steve D Pate, "Unix Internals: A practical Approach", ADDISON-WESLEY, pp.310-320, 1996. 


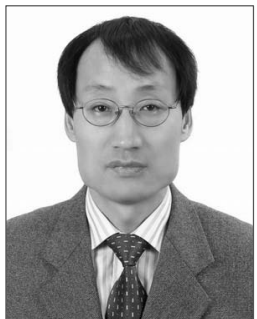

\section{이 형 봉}

e-mail :hblee@gwnu.ac.kr

1984년 서울대학교 계산통계학과(학사)

1986년 서울대학교 계산통계학과(석사)

1986년 1993년 LG전자 컴퓨터연구소 선임

1994년 1998년 한국디지탈(DEC Korea) 책임

2002년 강원대학교 컴퓨터과학과(박사)

1999년 2003년 호남대학교 정보통신공학부 조교수

2004년 현 재 강릉원주대학교 컴퓨터공학과 교수

관심분야: 임베디드 시스템, 센서 네트워크, 데이터마이닝 알고 리즘

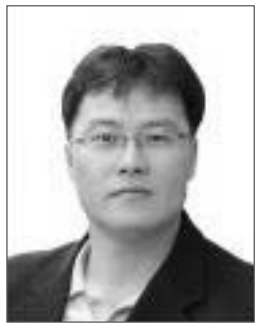

권 기 현

e-mail :kweon@kangwon.ac.kr 1993년 강원대학교 전자계산학과(학사) 1995년 강원대학교 전자계산학과(석사) 2000년 강원대학교 컴퓨터과학과(박사) 1998년 2002년 동원대학 인터넷정보과 교수

2002년 현 재 강원대학교 전자정보통신공학부 교수 관심분야: 패턴인식, 미들웨어, 임베디드 소프트웨어 